\title{
VINCRISTINE AFFECTS THE REDOX REACTIVITY OF HEMOGLOBIN
}

\author{
VICTORIA CÎRJEUa, CRISTINA PUȘCAȘ ${ }^{a}$, \\ RADU SILAGHI-DUMITRESCUं*
}

\begin{abstract}
The anticancer drug vincristine, known to act by inhibiting tubulin function in human cells, is shown to affect autoxidation rates in hemoglobin either alone or under conditions where nitrite acts as an initiator in a nitrosative stress cascade. This behavior mirrors those observed by us with four other antitubulin agents - irinotecan, docetaxel, paclitaxel and vinorelbine.
\end{abstract}

Keywords: vincristine, hemoglobin, autoxidation, nitrite, oxidative stress, nitrosative stress, UV-vis

\section{INTRODUCTION}

Anticancer agents have a wide variety of mechanisms by which they interfere with the growth of tumor cells. The largest group are agents that interact with DNA (by blocking DNA synthesis or by incorporation into DNA). Another important class of anticancer drugs is that of the antitubulin agents, which also affect cell division - but this time by interacting with protein scaffolds rather than with DNA [1-5]. Beyond these mechanisms, or often due precisely to them, chemotherapy can entail debilitating side effects such as bone marrow suppression, gastrointestinal damage, hair loss or nausea $[1,2]$.

Hemoglobin $(\mathrm{Hb})$ is found in large amounts in the blood and is among the first proteins in the human body to come into contact with anticancer drugs, so it is relevant to study the influence of cytotoxic compounds on it to understand the side effects of chemotherapy. Beyond its oxy/deoxy equilibrium in the ferrous state, $\mathrm{Hb}$ undergoes a range of redox reactions in blood as well as (or especially) in cases where it escapes the blood vessels

\footnotetext{
a Babeş-Bolyai University, Faculty of Chemistry and Chemical Engineering, 11 Arany Janos str., RO-400028, Cluj-Napoca, Romania

*Corresponding author: rsilaghi@chem.ubbcluj.ro
} 
in cases such as injury (e.g., subarachnoid hemorrhage). These redox reactions include autoxidation to ferric (met) $\mathrm{Hb}$ with liberation of superoxide and subsequently hydrogen peroxide, reaction with nitrosative stress agents such as nitrite, or reaction with oxidative stress agents such as peroxides. The chemical products of these reactions, as well as their biomedical relevance, have been explored to some length $[6,7,16,17,8-15]$. We have recently shown that cisplatin and related platinum complexes, as well as organic anticancer drugs and drug candidates, have the ability to affect the redox reactivity of hemoglobin - in terms of autoxidation rates, reactivity towards peroxides, and reactivity towards nitrite. These effects appear to entail $\mathrm{Hb}$-drug complexes as well as direct redox reactions between the drug and hemoglobin and or small-molecules stress agents [1,2,4,5,16,18-20].

Vincristine (IUPAC (3aR, 3a1R, 4R, 5S, 5aR, 10bR) -methyl 4acetoxy-3a-ethyl-9 - ((5S, 7S, 9S) -5-ethyl-5-hydroxy-9- (methoxycarbonyl) 2, 4,5,6,7,8,9,10-octahydro-1H-3,7-methane [1] azacycloundecino [5,4-b] indol-9-yl) -6-formyl-5 -hydroxy-8-methoxy-3a, 3a1,4,5,5a, 6,11,12-octahydro$1 \mathrm{H}$-indolizino [8,1-cd] carbazole-5-carboxylate), also known as leurocristine, is a colorless drug from the class of Vinca alkaloids used in chemotherapy to treat various types of cancer such as acute lymphocytic leukemia, acute myeloid leukemia, Hodgkin's disease, lung cancer, neuroblastoma and others. Vincristine is given intravenously, typically from preparations at $\sim 1 \mathrm{mM}$ concentration and in amounts equating to $1 \mu \mathrm{M}$ concentration in blood, and, like other Vinca alkaloids, binds to tubulin and blocks mitosis. X-ray analysis showed that the drug binds equally to $\alpha$ and $\beta$-tubulin and causes a curvature at the interface that leads to the spiraling of protofilaments, subsequently reacting with their unstable end and inhibiting protein polymerization, eventually resulting in cell death [21-26]. We have recently explored the reactivity of hemoglobin towards a set of four anti-tubulin agents - irinotecan, docetaxel, paclitaxel and vinorelbine - and found that they affect the $\mathrm{Hb}$ autoxidation rates (either alone or in assays where nitrite accelerates autoxidation via a cascade of nitrosative stress reactions) and, for members with more extended aromatic rings (and hence with measurable electronic absorption spectra in the visible domain), they can also serve as direct redox partners acting to reduce high-valent hemoglobin in the presence of peroxide [1].

Reported here is an exploration of $\mathrm{Hb}$ reactivity towards vincristine, employing UV-vis spectroscopy and showing similar behavior to that previously observed for other anti-tubulin agents - with two particularities: the effect on $\mathrm{Hb}$ autoxidation is very small, while the effect on nitrite-induced autoxidation is remarkably antioxidant. 


\section{RESULTS AND DISCUSSION}

Figure 1 shows UV-vis spectra collected for oxy hemoglobin before and after incubation with $50 \mu \mathrm{M}$ vincristine up to 4 hours. There appear to be no discernible differences in the Soret band at $\sim 400 \mathrm{~nm}$. However, closer inspection of the bands at $577 \mathrm{~nm}$ (specific to oxy $\mathrm{Hb}$ cf. Figure 1) and 630 $\mathrm{nm}$ (specific to autoxidized, met $\mathrm{Hb}$, cf. Figure 1) does reveal an (albeit small) influence of vincristine in accelerating autoxidation. Table 1 further shows that the ratio of the oxy to met features ( $577 \mathrm{vs.} 630 \mathrm{~nm}$ ) in the $\mathrm{Hb}$ spectrum increases with vincristine concentration up to $75 \mu \mathrm{M}$.

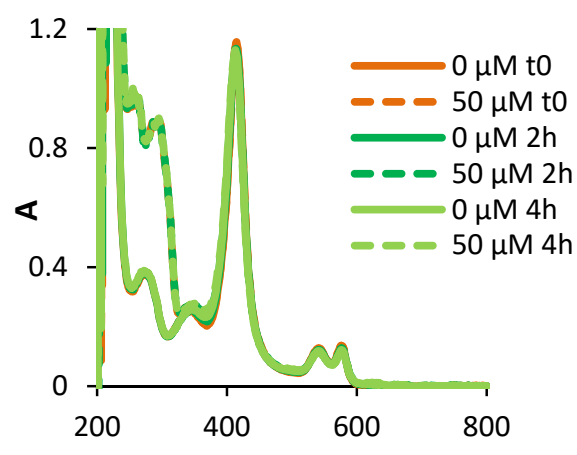

$\mathrm{nm}$

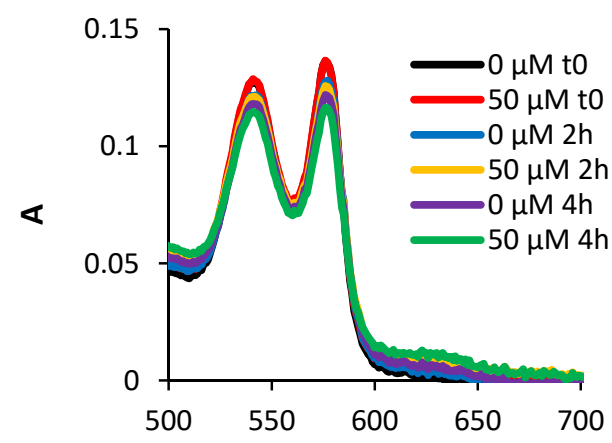

$\mathrm{nm}$

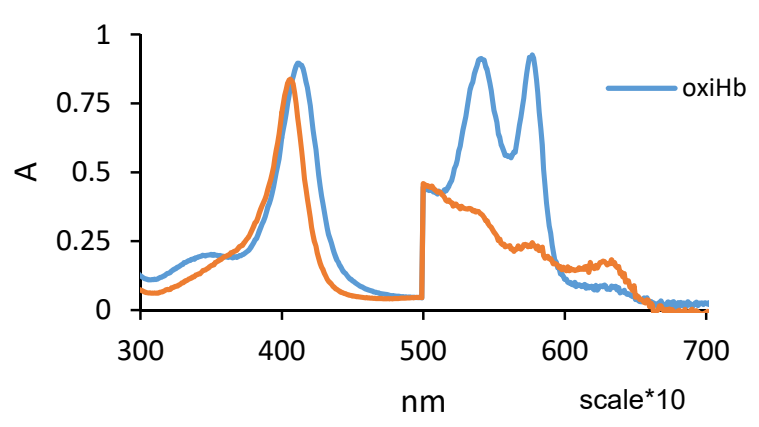

Figure 1. Top row: time dependence of oxy Hb UV-vis spectra with or without vincristine present. Lower row: reference spectra of oxy and met $\mathrm{Hb}$.

Table 1. Met:oxy ratio (calculated as the ratio of absorbance at $630 \mathrm{~nm}$ vs. absorbance at $577 \mathrm{~nm}$ ) from UV-vis spectra collected after 4 hours at $37^{\circ} \mathrm{C}$.

\begin{tabular}{|c|c|c|c|c|c|c|}
\hline vincristine $(\mu \mathrm{M})$ & 0 & 10 & 25 & 50 & 75 & 100 \\
\hline met:oxy ratio & 0.05 & 0.07 & 0.07 & 0.09 & 0.12 & 0.08 \\
\hline
\end{tabular}


The UV-vis spectra of red blood cells (Figure 2) are not affected by vincristine at concentrations of up to $50 \mu \mathrm{M}$ immediately after mixing. However, after incubation at $37^{\circ} \mathrm{C}$ for 4 hours, the Soret band in the $50-\mu \mathrm{M}$ sample is distinctly higher than that of the other two samples ( 0 and $10 \mu \mathrm{M}$ vincristine, respectively). In erythrocytes the UV-vis spectrum is due almost exclusively to $\mathrm{Hb}$; however, the intensity of the Soret band is additionally affected by the integrity of the cells: erythrocyte damage from oxidative stress upon $\mathrm{Hb}$ autoxidation appears to increase the intensity of the Soret band even when the 500-700 nm region reveals no change in the oxidation state of $\mathrm{Hb}$ [16]. We therefore propose that at 4 hours a $50 \mu \mathrm{M}$ concentration of vincristine (but not a concentration of $10 \mu \mathrm{M}$ ) can induce optically-detectable changes in the state of the red blood cells. It is important to note that such cell lysis cannot be a direct result of $\mathrm{Hb}$ autoxidation; rather, autoxidation initially places oxidative stress (via the liberated superoxide) upon the cell. One may expect an initial phase where the cell structure remains intact but the antioxidant reserves (ascorbate, thiols, NADPH and others $[27,28]$ ) are consumed. Such a form of stress may then be expected to have manifested itself even in the $10 \mu \mathrm{M}$ sample; this hypothesis would require subsequent tests on molecular markers of oxidative stress, other than $\mathrm{Hb}$ itself.

After incubation of erythrocytes overnight (as also shown in Figure 2), the Soret peak has now clearly shifted to $405 \mathrm{~nm}$ (specific to met $\mathrm{Hb}$ ) from the initial 410 value in fresh (oxy) samples. Similarly to the 4-hour samples, there is a monotonous increase in absorbance from 800 to $200 \mathrm{~nm}$, superimposed over the $\mathrm{Hb}$ absorption. This increase is due to diffuse/particulate matter in the sample, most likely protein precipitation; its degree does not appear to be increased proportionally with vincristine concentration.

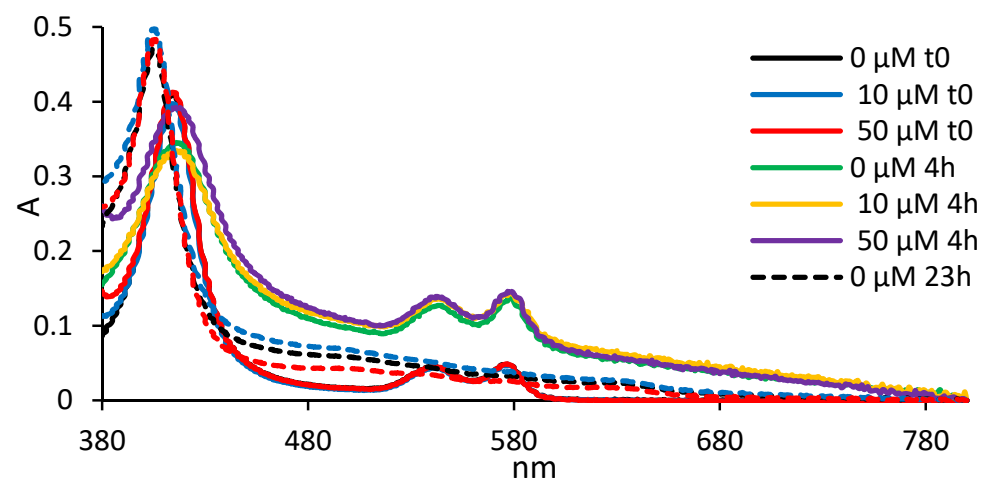

Figure 2. UV-vis spectra of erythrocytes re-suspended in saline phosphate buffer $\mathrm{pH}$ 7.4 , with or without vincristine at two different concentrations, after incubation at $37^{\circ} \mathrm{C}$. 
Last but not least, Figure 3 shows the effect of vincristine on the nitrite-induced oxidation of $\mathrm{Hb}$. In this assay, the initial step is reaction of nitrite with oxy $\mathrm{Hb}$ to form a caged ferric-peroxynitrate intermediate. However, clear changes in absorbance (e.g., at the oxy bands such as $\sim 540$ or $\sim 580$ $\mathrm{nm})$ are not seen at these low nitrite concentrations until enough side-products (nitrogen oxides, superoxide, and others) accumulate. Hence, the key feature of the reaction time course is the lag time. Any added reactant (e.g., the vincristine) may be expected to affect the reaction either by delaying the change in absorbance (thus protecting the oxy form of $\mathrm{Hb}$ - and hence acting as antioxidant), or by shortening the lag time (thus acting as prooxidant). Figure 3 shows that already at a very low concentration, $30 \mu \mathrm{M}$, vincristine completely blocks the reaction - thus acting as a very efficient protecting agent against nitrosative stress on $\mathrm{Hb}$.

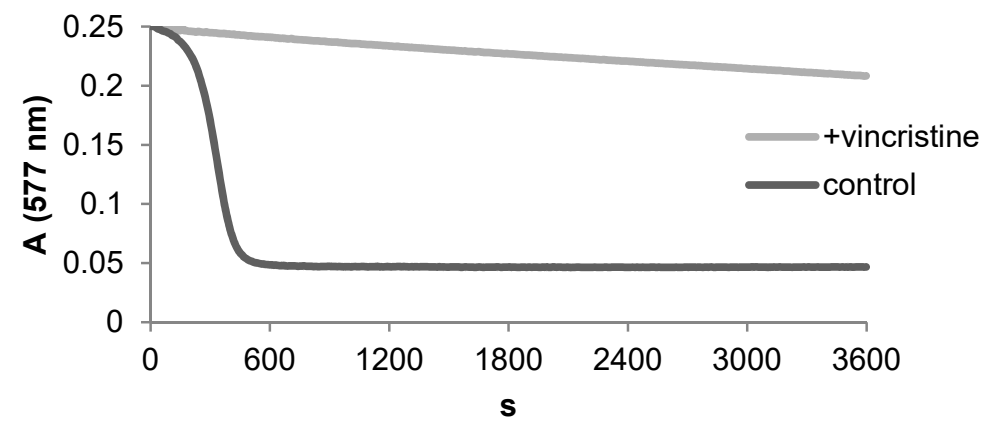

Figure 3. Influence of vincristine on the time evolution of oxy $\mathrm{Hb}$ absorbance in the presence of nitrite.

\section{CONCLUSIONS}

Vincristine has a very small (concentration-dependent) accelerating effect on $\mathrm{Hb}$ autoxidation in vitro in the concentration range 10-100 $\mu \mathrm{M}$. At $50 \mu \mathrm{M}$, it also affects the stability of red blood cells. Vincristine also displays a powerful inhibitory effect on the (in vitro) nitrite-induced oxidation of $\mathrm{Hb}$. The concentration ranges examined in the present study may be bio-medically relevant, since intravenous injections of vincristine in anticancer treatments are given with $\sim 1000 \mu \mathrm{M}$ solutions (although one must also note that after dilution in the total blood volume of a patient, even before the drug can exit to various organs in the body, the vincristine concentration would eventually not exceed $1 \mu \mathrm{M}$ ). Further examination at lower concentrations of vincristine 
and on other types of cells would be warranted - though in those cases specific molecular markers would have to be measured, other than the very convenient $\mathrm{Hb}$ absorbance in UV-vis examined in the present study.

\section{EXPERIMENTAL SECTION}

Bovine hemoglobin was purified following the general protocol of Antonini and Brunori as previously described [29], and stored in saline (PBS), $\mathrm{pH}$ 7.4. In order to ensure a homogeneous (oxy) composition, the protein was first treated with sodium dithionite and passed through a desalination column. The hemoglobin concentration is given per heme. Vincristine was used as aqueous solutions prepared by mixing solid powder (drug) with saline $(0.9 \% \mathrm{NaCl})$ without further purification. Electronic absorption were recorded with a Cary 50 instrument (Varian, Inc) in the range of $200-800 \mathrm{~nm}$, in $1 \mathrm{~mL}$ quartz cuvettes.

Autoxidation of $\mathrm{Hb}(10 \mu \mathrm{M})$ in the presence of vincristine (at concentrations given in Figures) was monitored in PBS saline, $\mathrm{pH} 7.4$, with the samples incubated at $37^{\circ} \mathrm{C}$. Red blood cells were examined under similar conditions, using $30 \mu \mathrm{L}$ of sample instead of $10 \mu \mathrm{M}$ pure $\mathrm{Hb}$.

Nitrite-induced autoxidation of was performed using oxyHb $(240 \mu \mathrm{M})$, nitrite $(334 \mu \mathrm{M})$ and vincristine $(30 \mu \mathrm{M})$ in PBS at room temperature. experiments.

All results to be analyzed represent the average of at least 3

\section{ACKNOWLEDGMENTS}

Dr. Eva Fischer-Fodor (IOCN) is thanked for kindly supplying a sample of vincristine. Dr. Alina Matei and drd. Maria Lehene (UBB) are thanked for helpful discussions. Prof. Bogdan Sevastre (USAMV Cluj-Napoca) is thanked for supplying bovine blood.

\section{REFERENCES}

1. C. Puscas; A. Mircea; M. Raiu; M. Mic; A.A.A. Attia; R. Silaghi-Dumitrescu; A.A. A. Attia; R. Silaghi-Dumitrescu; Chem. Res. Toxicol. 2019, 32, 1402-1411.

2. C. Bischin; V. Taciuc; R. Silaghi-Dumitrescu; in Metal Elements in Environment, Medicine and Biology (ed. Radu Silaghi-Dumitrescu G. G.) (Eurobit Publishing House, 2010). X, 265-270. 
3. C. Bischin; Ş. Tălu; R. Silaghi-Dumitrescu; M. Tălu; S. Giovanzana; C.A. Lupaşcu; Ann. Rom. Soc. Cell Biol. 2012, 17,

4. V. Taciuc; C. Bischin; R. Silaghi-Dumitrescu; in Metal Elements in Environment, Medicine and Biology Tome IX (eds. Silaghi-Dumitrescu R. \& Garban G.) (Cluj University Press, 2009). 130-134.

5. C. Bischin; V. Taciuc; R. Silaghi-Dumitrescu; Studia UBB Chem. 2010, 55, 313318.

6. N.B. Vollaard; B.J. Reeder; J.P. Shearman; P. Menu; M.T. Wilson; C.E. Cooper; Free Radic. Biol .Med. 2005, 39, 1216-1228.

7. C.E. Cooper; D.J. Schaer; P.W. Buehler; M.T. Wilson; B.J. Reeder; G. Silkstone; D.A. Svistunenko; L. Bulow; A. I. Alayash; Antioxidants Redox Signal. 2013, 18, 2264-2273.

8. B.J. Reeder; M.T. Wilson; Free. Radic. Biol. Med. 2001, 30, 1311-1318.

9. M.S. Rogers; R.P. Patel; B.J. Reeder; P. Sarti; M.T. Wilson; A.I. Alayash; Biochem. J. 1995, 310, 827-833.

10. B.J. Reeder; M.A. Sharpe; A.D. Kay; M. Kerr; K. Moore; M.T. Wilson; Biochem. Soc. Trans. 2002, 30, 745-748.

11. B.J. Reeder; M. Grey; R.-L. Silaghi-Dumitrescu; D.A. Svistunenko; L. Bülow; C.E. Cooper; M.T. Wilson; J. Biol. Chem. 2008, 283, 30780-30787.

12. B.J. Reeder; D.A. Svistunenko; M.A. Sharpe; M.T. Wilson; Biochemistry 2002, 41, 367-375.

13. S. Holt; B.J. Reeder; M.T. Wilson; S. Harvey; J.D. Morrow; L.J. Roberts 2nd; K. Moore; L.J. Roberts; K. Moore; L.J. Roberts 2nd; K. Moore; L.J. Roberts; K. Moore; Lancet 1999, 353, 1241.

14. B.J. Reeder; D.A. Svistunenko; C.E. Cooper; M.T. Wilson; Antioxidants Redox Signal. 2004, 6, 954-966.

15. K.P. Moore; S.G. Holt; R.P. Patel; D.A. Svistunenko; W. Zackert; D. Goodier; B.J. Reeder; M. Clozel; R. Anand; C.E. Cooper; J.D. Morrow; M.T. Wilson; V.M. DarleyUsmar; L.J. Roberts; V. Darley-Usmar; L.J. Roberts 2nd; L.J. Roberts 2nd; V.M. DarleyUsmar; L.J. Roberts; J. Biol. Chem. 1998, 273, 31731-31737.

16. M. Lehene; E. Fischer-Fodor; F. Scurtu; N.D. Hădade; E. Gal; A.C. Mot; A. Matei; R. Silaghi-Dumitrescu; Pharmaceuticals 2020, 13, 107.

17. D. Hathazi; F. Scurtu; C. Bischin; A. Mot; A. Attia; J. Kongsted; R. SilaghiDumitrescu; Molecules 2018, 23, E350.

18. L.I. Găină; L.N. Mătărângă-Popa; E. Gal; P. Boar; P. Lönnecke; E. HeyHawkins; C. Bischin; R. Silaghi-Dumitrescu; I. Lupan; C. Cristea; L. SilaghiDumitrescu; Eur. J. Org. Chem. 2013, 5500-5508.

19. L. Gaina; I. Torje; E. Gal; A. Lupan; C. Bischin; R. Silaghi-Dumitrescu; G. Damian; P. Lonnecke; C. Cristea; L. Silaghi-Dumitrescu; Dye. Pigment. 2014, 102, 315-325.

20. C. Bischin; C. Tusan; A. Bartok; R. Septelean; G. Damian; R. SilaghiDumitrescu; Phosphorus, Sulfur Silicon Relat. Elem. 2015, 190, 292-299.

21. F. Liu; J. Huang; Z. Liu; Neuroscience 2019, 404, 530-540.

22. L. Zhou; L. Ao; Y. Yan; C. Li; W. Li; A. Ye; J. Liu; Y. Hu; W. Fang; Y. Li; Neurotherapeutics 2020, 17, 340-355. 
23. M.E. Duckett; K.M. Curran; H.J. Leeper; C.E. Ruby; S. Bracha; Vet. Comp. Oncol. 2021, 19, 61-68.

24. J.A. Silverman; S.R. Deitcher; Cancer Chemother. Pharmacol. 2013, 71, 555564.

25. L.D. Brühwiler; D.L.B. Schwappach; J. Oncol. Pharm. Pract. 2020, 26, 51-59.

26. M.L. Madsen; H. Due; N. Ejskjær; P. Jensen; J. Madsen; K. Dybkær; Cancer Chemother. Pharmacol. 2019, 84, 471-485.

27. C.E. Cooper; R. Silaghi-Dumitrescu; M. Rukengwa; A.I.I. Alayash; P.W.W. Buehler; Biochim. Biophys. Acta 2008, 1784, 1415-1420.

28. B.N. Ames; R. Cathcart; E. Schwiers; P. Hochstein; Proc. Natl. Acad. Sci. U.S.A. 1981, 78, 6858-6862.

29. D. Hathazi; A.C. Mot; A. Vaida; F. Scurtu; I. Lupan; E. Fischer-Fodor; G. Damian; D.M. Kurtz Jr.; R. Silaghi-Dumitescu; Biomacromolecules 2014, 15, 1920-1927. 